\title{
In-Depth Understanding of Fatigue Micromechanisms in Cemented Carbides: Implications for Optimal Microstructural Tailoring ${ }^{\dagger}$
}

\author{
Luis Llanes $1,2, *(\mathbb{D}$ \\ 1 Center for Structural Integrity, Micromechanics and Reliability of Materials-CIEFMA, Department Materials \\ Science and Metallurgy, Barcelona-East School of Engineering (EEBE), Campus Diagonal Besòs, \\ Universitat Politècnica de Catalunya-BarcelonaTech, E-08019 Barcelona, Spain \\ 2 Barcelona Research Center in Multiscale Science and Engineering, Campus Diagonal Besòs, \\ Universitat Politècnica de Catalunya-BarcelonaTech, E-08019 Barcelona, Spain \\ + This full paper corresponds to oral presentation given by the author as Keynote Speech in WorldPM 2018, \\ Beijing, China, 16-20 September 2018.
}

Received: 2 August 2019; Accepted: 22 August 2019; Published: 23 August 2019

\begin{abstract}
The fatigue mechanics and mechanisms of cemented carbides (composites usually referred to as hardmetals) are reviewed. The influence of microstructure on strength lessening and subcritical crack growth for these ceramic-metal materials when subjected to cyclic loads are highlighted. The simultaneous role of the ductile metallic binder as a toughening and fatigue-susceptible agent for hardmetals results in a tradeoff between properties measured under monotonic and cyclic loading: fracture strength and toughness on one hand, as compared to fatigue strength and crack growth resistance on the other one. Toughness/fatigue-microstructure correlations are analyzed and rationalized on the basis of specific crack-microstructure interactions, documented by the effective implementation of advanced characterization techniques. As a result, it is concluded that the fatigue sensitivity of cemented carbides may be reduced if either toughening mechanisms beyond ductile ligament bridging, such as crack deflection, are operative, or strain localization within the binder is suppressed. In this regard, grades exhibiting metallic binders of a complex chemical nature and/or distinct microstructural assemblages are proposed as options for effective microstructural tailoring of these materials.
\end{abstract}

Keywords: cemented carbides; fatigue strength; fatigue crack growth; fatigue sensitivity; fatigue micromechanisms

\section{Introduction}

Fatigue is a relevant service degradation phenomenon in cemented carbides (materials also referred to as hardmetals). It is associated with premature and unexpected failure during their application as structural components, e.g., cutting or forming tools. However, different from the case of hardness, strength, toughness, and wear resistance, parameters for which there exist comprehensive literature surveys about the influence of microstructure, similar information on the fatigue behavior for these materials is significantly less extensive (e.g., Sarin et al. [1]).

Although the earliest information on fatigue of cemented carbides dates from more than 70 years ago [2], the more relevant scientific and technical advances on this field have been reported in the last three decades. Among them, the findings reported by Sockel's [3-6] and Llanes's [7,8] groups are noteworthy. Regarding the former, based on the applied stress-fatigue life (S-N curves) data, Schleinkofer and co-workers documented a relevant fatigue strength-lessening associated with damage localization within the ductile binder phase [3,4]. It was directly linked to subcritical crack growth 
of pre-existing flaws, pointing out this stage as the controlling one for failure under cyclic loading in hardmetals [3-5]. Concerning the later, Torres and co-workers postulated and validated the fatigue crack growth (FCG) threshold as the effective toughness under cyclic loading [7]. An extensive and systematic analysis of the FCG data gathered for a wide range of microstructurally different cemented carbides indicated the relevant influence of binder mean free path on the fatigue sensitivity of these materials [8]. As most of the experimental work done on cemented carbides has been conducted in tungsten carbide (WC)-Co systems, fatigue susceptibility of the metallic binder has been rationalized on the basis of phase transformation (fcc to hcp) induced by cyclic strain within the Co binder [3,4]. Therefore, the potential substitution of cobalt by alternative binders, based on either $\mathrm{Ni}$ or $\mathrm{Fe}$, has repeatedly emerged as an option for enhancing the fatigue resistance of hardmetals. Furthermore, literature data combining fracture and fatigue characteristics for cemented carbides are mainly concentrated on relatively finer-grained grades (e.g., References [3-9]). Considering that many fatigue-related applications (e.g., mining) involve tougher grades characterized by coarser microstructures, lack of this information is relevant for both design and optimal material selection. Following the above ideas, an updated version of the review published by the author's team about five years ago [9] is presented. It includes and emphasizes research recently conducted with the main objectives of evaluating the influence of the binder chemical nature and content, as well as that of microstructural coarsening on the FCG behavior of the referred materials. It has been done by assessing fatigue response and mechanisms, the latter through implementation of advanced characterization techniques such as focused ion beam (FIB) combined with scanning electron microscopy (SEM).

\section{Fatigue Mechanics}

Based on the fact that subcritical growth of either processing or service-induced flaws is the controlling stage for fatigue failure in cemented carbides, research conducted by Llanes and co-workers since the early 2000s has aimed to extend fracture mechanics concepts to studies of fatigue. However, it has not be done following the traditional damage tolerance methodology (i.e., one based on a direct FCG-fatigue life relationships) because of the extremely large power-law dependence of FCG rates on $\Delta K$ (or $K_{\max }$ ) exhibited by hardmetals [7,8,10,11]. Instead, a more practical approach has been proposed and validated by defining the FCG threshold $\left(K_{t h}\right)$ as the effective toughness under fatigue for a given critical flaw size. Under these conditions, the fatigue limit $\left(\sigma_{f}\right)$-corresponding to an infinite fatigue life-could be estimated from the expression $\sigma_{f}=Y^{-1}\left(K_{t h} / a_{c r}{ }^{1 / 2}\right)$. In this equation, $K_{t h}$ represents the stress intensity factor threshold of a small non-propagating crack emanating from a defect of critical size, $2 a_{c r}$, and $Y$ is a dimensionless factor that depends on the crack length, component geometry, and loading state. It should be noted that, within the referred equation, $K_{t h}$ and $\sigma_{f}$ are given in terms of applied $K_{\max }$ and $\sigma_{\max }$ respectively. The reason behind is that it is now well-established that $K_{\max }$ prevails over $\Delta K$ as the controlling fracture mechanics parameter for describing FCG kinetics of hardmetals using a modified Paris-Erdogan relationship, as it will be further discussed later $[8,10,11]$.

The above approach required that the fundamental linear elastic fracture mechanics (LEFM) correlation-involving strength, stress intensity factor, and defect size-holds valid for processing defects in the materials under consideration. Such an assumption is completely supported by several experimental facts. First, critical natural flaws are larger in size than the microstructural unit. Second, plasticity is confined to the process zone ahead of the crack tip. And third, fracture is controlled by a multiligament zone behind the crack tip that just extends about five ligaments (i.e., a relatively short distance) [12-14]. Within this context, it may be assumed that strength-controlling defects are independent of the loading mode, and thus, fatigue limit $\left(\sigma_{f}\right)$ values can be estimated from the relation $\sigma_{f}=\sigma_{r}\left(K_{t h} / K_{I c}\right)$, where $\sigma_{r}$ represents the strength measured under monotonic loading.

For some specific grades attempting to validate the estimated fatigue limit, experimental studies have been conducted using a large enough number of samples and following an up-and-down load (stair-case) fatigue test. 
Figure 1 summarizes the fatigue mechanics framework just described on the basis of different experimental testing and data analysis boxes. On the one hand, it emphasizes the "input" role of parameters experimentally measured under monotonic (strength and fracture toughness) and cyclic (FCG threshold) loading for estimating as an "output" the fatigue limit of the material under study through the expression $\sigma_{f}=\sigma_{r}\left(K_{t h} / K_{I c}\right)$. On the other hand, validation is given by the excellent agreement between the estimated fatigue limit values and those determined through stair-case fatigue testing in selected grades (optional "input"), as well as identification of similar critical flaws, as discerned from fractographic analysis of broken specimens, independent of the loading mode.

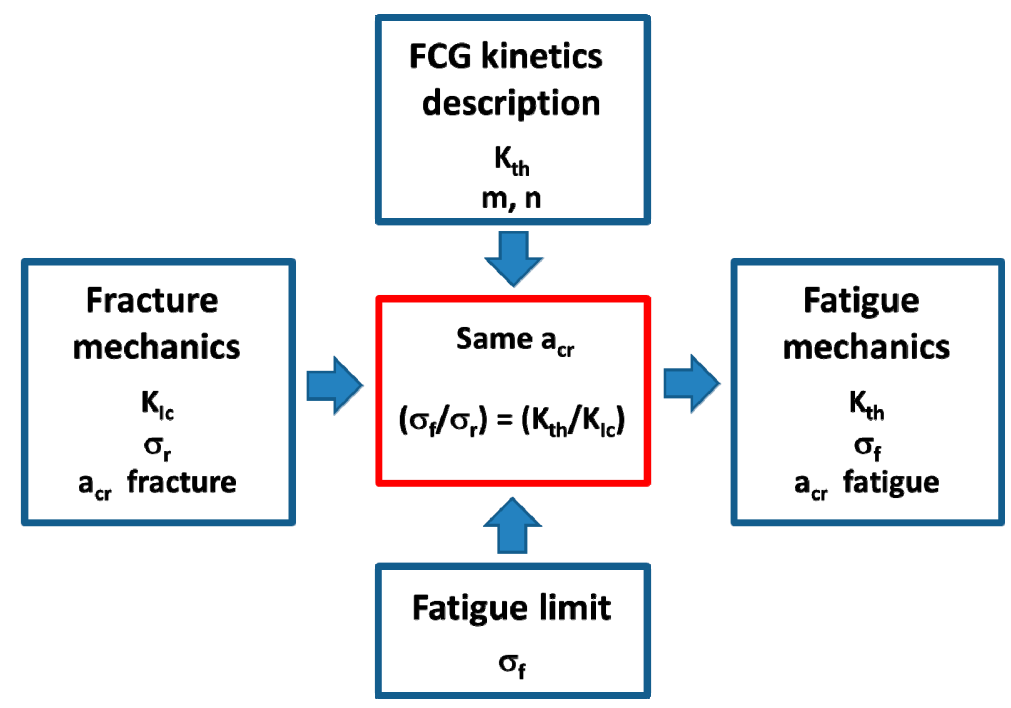

Figure 1. Estimation of fatigue limit following a fatigue mechanics approach.

Tarragó and coworkers $[13,15,16]$ have implemented the above protocol in several microstructurally different cemented carbides in terms of the binder chemical nature (either $\mathrm{Co}$ or $\mathrm{Ni}$ or $\mathrm{CoNi}$ ) and content (between 10 and $15 \mathrm{wt} \%$ ), as well as carbide grain size (between 0.4 and $2.4 \mu \mathrm{m}$ ). In general, an excellent agreement is obtained between the predicted, using $\sigma_{f}=\sigma_{r}\left(K_{t h} / K_{I c}\right)$, and experimentally determined fatigue limits, validating the FCG threshold-fatigue limit correlation as general for all the cemented carbides studied. Furthermore, the fractographic examination conducted on failed specimens revealed that the size, geometry, and nature of the critical defects are similar under both monotonic and cyclic loading conditions. However, under the application of cyclic loads, these defects act as starting locations for subcritical crack growth until they reach a critical size where unstable fracture takes place. From this viewpoint, it is interesting to highlight other studies where different inspection approaches or testing variants are involved. On the one hand, fractographic analysis has been used for invoking correlations between fatigue life and the size of microstructural defects on the basis of Murakami's geometrical parameter of maximum flaw area [17-19]. On the other hand, notched specimens have been used for assessing microstructural effects on fatigue response under service-like conditions, e.g., presence of stress concentrators in component geometry as crack starting points and exposure to high temperatures $[17,20-23]$.

\section{Fatigue Sensitivity}

Concerning FCG behavior, as referred to above, the existence of a strong dependence of FCG rates on fracture mechanics parameters is well-established. In this regard, a modified Paris-Erdogan relationship of type $\mathrm{da} / \mathrm{dN}=C K_{\max }{ }^{m} \Delta K^{n}$, may be used for describing FCG kinetics of cemented carbides. It has been proven to apply for other brittle-like materials such as structural ceramics (e.g., References [24,25]). The implementation of such an analysis approach has allowed Llanes et al. [8] to discern an inverse correlation between the mean binder free path and the prevalence of $K_{\max }$ over 
$\Delta K(\mathrm{~m} / \mathrm{n}$ ratio) as the controlling fracture mechanics parameter. It was associated with an increasing predominance of static over cyclic modes of fracture during stable FCG as the mean binder free path becomes smaller. Very interestingly, it was also observed that as the binder thickness gets larger (or carbide contiguity gets lower), the FCG threshold values were more affected than the fracture toughness values. Such behavior points out a higher fatigue sensitivity, in terms of crack growth resistance, for tougher hardmetals. These findings are in total agreement with results reported (on the basis of S-N data) by Sailer et al. [6], and sustain the use of fatigue sensitivity, a parameter defined as $\left[1-\left(K_{t h} / K_{I c}\right)\right]$, and thus ranges from 0 (ceramic-like) to 1 (metallic-like), for the direct estimation of fatigue limit values for cemented carbides. From a physical viewpoint, the metallic nature of the binder should be invoked to rationalize the higher fatigue sensitivity of tougher hardmetals, as metals are intrinsically tough but also fatigue-susceptible materials. In this regard, the two-phase microstructural assemblage of cemented carbides should be highlighted, as it defines the effective thickness of the metallic binder (mean free path, $\lambda_{\text {binder }}$ ), and thus, the effective ductility of this phase, resulting from the real constraint imposed on it by the surrounding very rigid carbide crystals. This microstructure-property correlation then becomes relevant for understanding the transition exhibited by hardmetals from ceramic-like to metallic-like FCG behavior, together with a higher prominence of the trade-off between fracture toughness and FCG resistance as binder thickness rises (Figure 2).

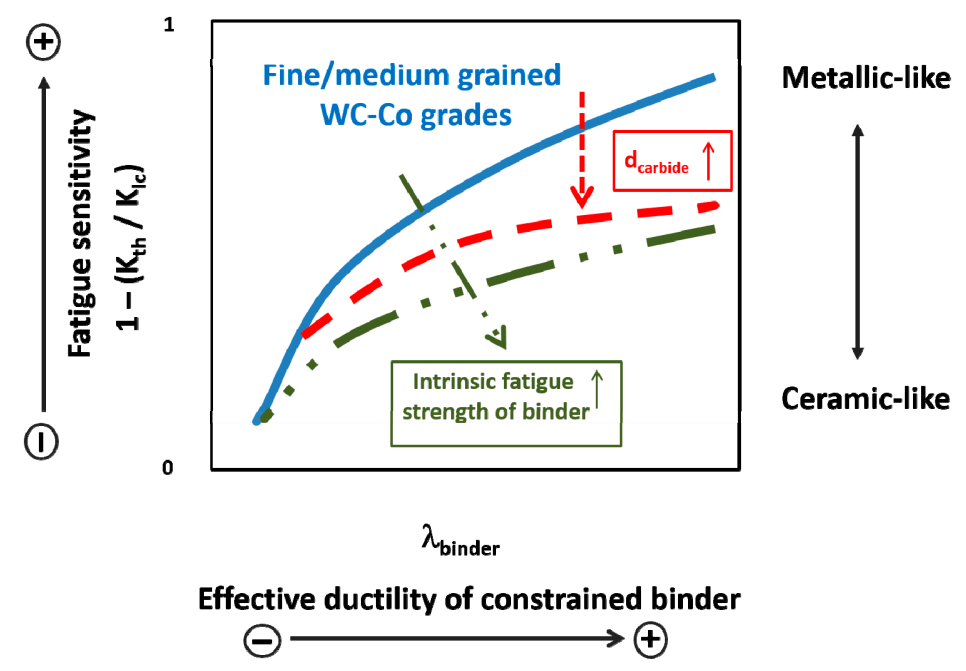

Figure 2. Fatigue sensitivity-microstructure relationship for cemented carbides.

Recent investigations on coarse-grained cemented carbides have evidenced that the previously discussed correlation between fatigue sensitivity and binder mean free path is indeed more complex than initially proposed $[16,26]$. This is associated with the fact that as microstructure gets coarser, crack deflection (directly proportional to carbide grain size, $d_{\text {carbide }}$ ) becomes another relevant toughening mechanism, besides ductile ligament bridging and intrinsic crack growth resistance of WC. Considering that the presence and effectiveness of crack deflection as a toughening mechanism should not be affected by cyclic loading, it then yields noticeably lower fatigue sensitivity values (i.e., higher $K_{t h} / K_{I c}$ ratios) for coarser grades than for finer ones, even though they exhibit a similar effective binder thickness. In contrast, no relevant influence of binder chemical nature was discerned on either FCG threshold or fatigue sensitivity values, as far as grades with alike microstructures, in terms of carbide size and binder content, were compared $[15,16]$. This later finding will indicate that susceptibility to fatigue degradation of ductile $\mathrm{Co}, \mathrm{Ni}$, and $\mathrm{CoNi}$ binders is rather similar. 


\section{Crack-Microstructure Interaction under Monotonic and Cyclic Loading}

Crack-microstructure interaction may be evaluated directly at the surface through optical and scanning electron microscopy, at the subsurface (3D-like) by means of sectioning and imaging using FIB, or indirectly using fractographic examination. All these approaches are indeed complementary and require critical and special care for gathering effective information.

Toughening mechanisms have been discerned from the detailed examination of cracks stably grown under monotonic loading (Figure 3a). Surface and subsurface inspection have proven the existence of a well-defined multiligament zone, which is the basic premise for understanding toughness and crack growth resistance behavior in cemented carbides $[13,14,27]$. In this regard, the exceptional toughening exhibited by hardmetals may be described by the reinforcement mechanism exerted by ductile binder bridges at the crack wake [12]. The intrinsic ductile character of such ligaments implies a high amount of energy absorption during the nucleation, growth, and coalescence of microcavities during the local failure process. It commonly takes place within the binder, although close to either carbide corners or carbide-binder interfaces, where high triaxiality stress and strain conditions are fulfilled [28]. It is found that the size of the multiligament zone extends about 6-7 times the microstructural length scale of the hardmetal studied, thus comprising between 4 and 6 bridging ligaments [14]. As the microstructure gets coarser, the crack growth scenario becomes more complex because of competition between crack deflection (attempting to run through metallic binder) and/or transgranular carbide cracking, particularly for large carbides. As a result, crack paths are rather tortuous (non-planar), mainly following the metallic binder, but exhibiting pronounced and frequent deflections [26]. This is completely in agreement with features observed in the corresponding fracture surfaces: well-defined dimples within the metallic phase surrounded by constraining carbides exhibiting transgranular cleavage (Figure $4 a)$.

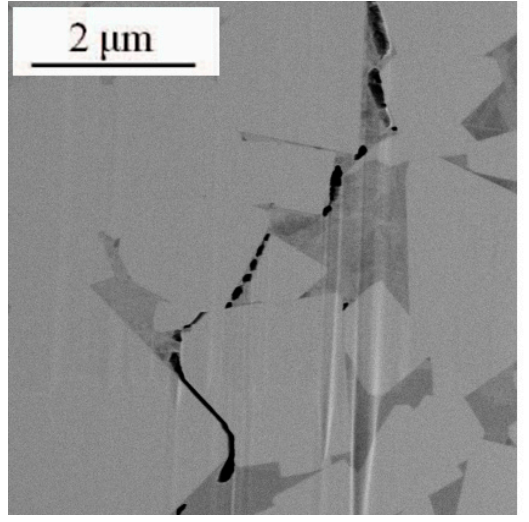

(a)

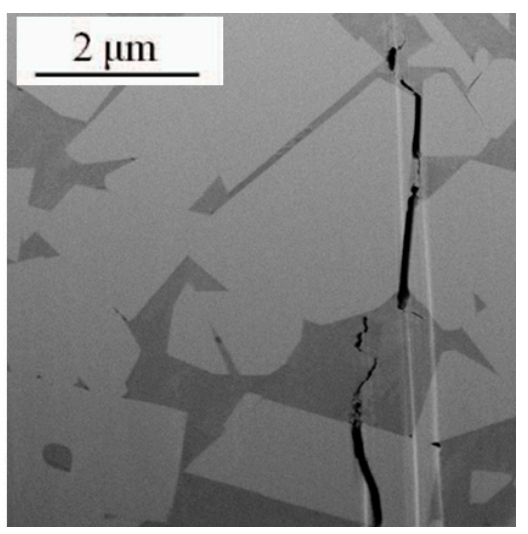

(b)

Figure 3. Representative crack-microstructure interaction under (a) monotonic and (b) cyclic loading in cemented carbides.

Different from the crack-microstructure interaction discerned under monotonic loading, fatigue micromechanisms in cemented carbides are less understood. Taking this into consideration, a 3D-like perspective attained using sequential "slice and view" FIB/SEM inspection has emerged as an ideal advanced characterization technique for identifying failure micromechanisms. In general, subcritical fatigue crack growth is more predominantly located in the ductile binder phase than under monotonic loading, where fatigue crack extension follows crystallographic-like paths (Figure 3b), and the fracture surface is characterized by sharp angular facets localized within broken binder regions (Figure 4b) $[13,15,16,26]$. Within this context, several interesting observations may be underlined. First, the fact that a faceted, crystallographic fracture mode had been mainly documented in fatigued WC-Co hardmetals $[8,13,26,29]$ has backed the idea of linking these micromechanisms to the fcc-to-hcp phase 
transformation of the Co-base binder. However, based on crystallographic analysis, the intrinsic origin of these steps is unclear, as they could be also related to slip-related shear bands or stacking faults. Furthermore, recent studies by Tarragó et al. [15,16] showing step-like markings on fatigue-fracture surfaces of nickel- and cobalt/nickel-base grades point out that fatigue susceptibility of cemented carbides goes beyond changes in the deformation mode induced by the referred phase transformation in Co-base binders. Second, similar crystallographic stable crack growth paths have also been reported in Co- and Ni-base alloys in the near-threshold FCG regime [30-32]. Considering that for Ni-base alloys and the WC-Ni hardmetal grade phase transformation mechanisms cannot be invoked, such fractographic morphology should instead be rationalized as a microstructure size scale effect. This statement is sustained by the similar dimensions of the representative microstructural scale (here approximately given by the binder mean free path) on one hand, and the size of the cyclic plastic zone $\left(r_{c} \approx(1 / \pi)\left(\Delta K_{I} / 2 \sigma_{y}\right)^{2}\right.$, where $\Delta K_{I}$ is the applied stress intensity factor range and $\sigma_{y}$ is the yield strength of the material) on the other. Such a condition is referred to as "typical" for defining the FCG threshold, as it is commonly found when the transition from the near-threshold regime to the intermediate stage is observed [33]. Inserting relatively high effective yield stress values (between 1 and $4 \mathrm{GPa}$ [34-38]) in the above $r_{\mathcal{C}}$ equation, together with those measured for $\Delta K_{I}$ (between 4 and $15 \mathrm{MPa} \cdot \mathrm{m}^{1 / 2}$ ), a sub-micrometric size for the plastic region ahead of the crack tip, i.e., close to length scale of the binder mean free path of the studied cemented carbides, is attained. Third, both surface and subsurface inspection clearly highlights that, different from other extrinsically-toughened brittle materials, the strength lessening under cyclic loads of cemented carbides must be rationalized via the suppression of toughening mechanisms (developed under monotonic loading) rather than the degradation of them. It means that, under cyclic loading, bridging ligaments are never formed rather than being broken once they have been developed. Within this context, the fatigue strength enhancement of cemented carbides should be approached in terms of direct improvement of the intrinsic fatigue resistance of the metallic binder. This will require either increasing the cyclic yield strength or decreasing the strain localization phenomena. It could be attempted through precipitation or two-phase hardening regarding the former, or by optimizing chemical nature aiming to control operative deformation mechanisms (i.e., slip bands, stacking faults, deformation or stress-induced twins, etc.) and/or slip mode (i.e., planar or wavy) concerning the latter. As relevant research efforts are nowadays dedicated to assessing alternative binders for developing new cemented carbides, the above ideas should also be considered if fatigue resistance, as a key structural design parameter, needs to be enhanced.

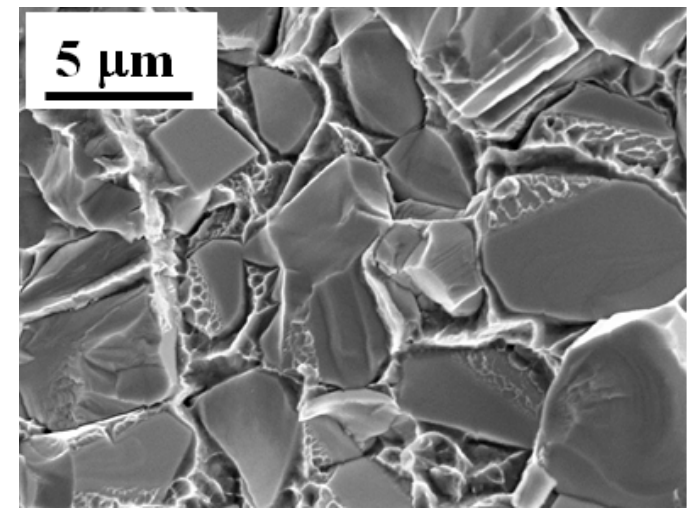

(a)

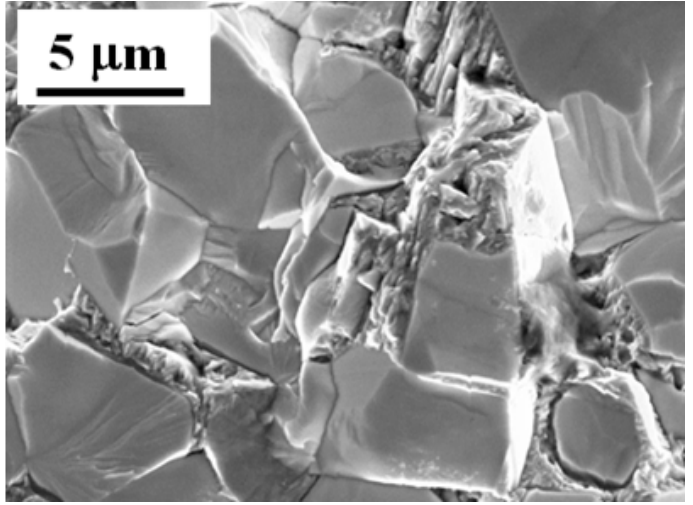

(b)

Figure 4. Representative fractographic scenario of (a) unstable (fast fracture) and (b) stable (fatigue) crack growth in cemented carbides. 


\section{Summary}

The range of both "emerging" and/or "to be consolidated" applications for cemented carbides is continuously increasing. In most of them, besides hardness, the consideration of toughness and fatigue resistance as critical design parameters is becoming mandatory. This is particularly true in the application of hardmetals as either forming tools or structural components. Here, reliability may be strongly enhanced by improving toughness and fatigue strength because it means a lower probability of premature and unexpected failures.

The main objective of this contribution has been to review the fatigue behavior of cemented carbides. Emphasis has been placed on describing and analyzing the influence of microstructure on fatigue strength and FCG for these materials. From the findings presented, it is clear that consideration of the two-phase microstructural assemblage, in terms of individual and combined effects of changing either the binder content and/or carbide grain size, is critical for understanding the trade-off existing between monotonic and cyclic properties. In this regard, two specific guidelines are pointed out for optimizing the microstructural design of cemented carbides against fatigue: (1) to enhance intrinsic resistance against strain localization under cyclic loading of the metallic binder; and (2) to introduce microstructure coarsening, either homogeneously or heterogeneously, as a key strategy to reduce fatigue sensitivity. Hence, deformation, fracture, and fatigue of grades with multi-alloyed metallic binders and/or exhibiting distinct microstructural assemblages (e.g., bimodal or gradient) are proposed as interesting topics for future research.

Funding: This research was funded by Ministerio de Economía y Competitividad (currently under grant MAT2015-70780-C4-3-P) in Spain, as well as by Direcció General de Recerca del Comissionat per a Universitats i Recerca de la Generalitat de Catalunya through recognition of CIEFMA as Grup de Recerca Consolidat (currently under grant 2017SGR933).

Acknowledgments: This work contains research developed over several years, within the context of four $\mathrm{PhD}$ theses. In this regard, I would like to acknowledge fellowships received from Agencia Española de Cooperación Internacional (MAEC-AECID) to Y. Torres and D. Coureaux, and from Sandvik Hard Materials/Sandvik Hyperion/Hyperion Materials \& Technologies through a collaborative industry/university program to J.M. Tarragó and D.A. Sandoval.

Conflicts of Interest: The author declares no conflict of interest.

\section{References}

1. Sarin, V.K.; Mari, D.; Llanes, L. Comprehensive Hard Materials; Elsevier Ltd.: Oxford, UK, 2014; Volume 1, pp. $1-538$.

2. Dawihl, W. Die wissenschaftlichen und technischen grudlagen der pulvermetallurgic und ihrer anwendungsbereiche. Stahl Eisen 1941, 61, 909-919.

3. Schleinkofer, U.; Sockel, H.-G.; Görting, K.; Heinrich, W. Microstructural processes during subcritical crack growth in hard metals and cermets under cyclic loads. Mater. Sci. Eng. A 1996, 209, 103-110. [CrossRef]

4. Schleinkofer, U.; Sockel, H.G.; Gorting, K.; Heinrich, W. Fatigue of hard metals and cermets. Mater. Sci. Eng. A 1996, 209, 313-317. [CrossRef]

5. Kursawe, S.; Pott, P.; Sockel, H.; Heinrich, W.; Wolf, M. On the influence of binder content and binder composition on the mechanical properties of hardmetals. Int. J. Refract. Met. Hard Mater. 2001, 19, 335-340. [CrossRef]

6. Sailer, T.; Herr, M.; Sockel, H.-G.; Schulte, R.; Feld, H.; Prakash, L. Microstructure and mechanical properties of ultrafine-grained hardmetals. Int. J. Refract. Met. Hard Mater. 2001, 19, 553-559. [CrossRef]

7. Torres, Y.; Anglada, M.; Llanes, L. Fatigue mechanics of WC-Co cemented carbides. Int. J. Refract. Met. Hard Mater. 2001, 19, 341-348. [CrossRef]

8. Llanes, L.; Torres, Y.; Anglada, M. On the fatigue crack growth behavior of WC-Co cemented carbides: Kinetics description, microstructural effects and fatigue sensitivity. Acta. Mater. 2002, 50, 2381-2393. [CrossRef]

9. Llanes, L.; Anglada, L.; Torres, M.Y. Fatigue of cemented carbides. In Comprehensive Hard Materials; Sarin, V.K., Mari, D., Llanes, L., Eds.; Elsevier Ltd.: Oxford, UK, 2014; Volume 1, pp. 345-362.

10. Almond, E.A.; Roebuck, B. Fatigue-crack growth in WC-Co hardmetals. Met. Technol. 1980, 2, 83-85. [CrossRef] 
11. Fry, P.R.; Garrett, G.G. Fatigue crack growth behaviour of tungsten carbide-cobalt hardmetals. J. Mater. Sci. 1988, 23, 2325-2338. [CrossRef]

12. Sigl, L.S.; Exner, H.E. Experimental study of the mechanics of fracture in WC-Co alloys. Met. Mater. Trans. A 1987, 18, 1299-1308. [CrossRef]

13. Tarragó, J.M.; Jiménez-Piqué, E.; Turón-Viñas, M.; Rivero, L.; Al-Dawery, I.; Schneider, L.; Llanes, L. Fracture and fatigue behavior of cemented carbides: 3D focused ion beam tomography of crack-microstructure interactions. Int. J. Powder Metall. 2014, 50, 1-10.

14. Tarragó, J.; Jimenez-Pique, E.; Schneider, L.; Casellas, D.; Torres, Y.; Llanes, L. FIB/FESEM experimental and analytical assessment of R-curve behavior of WC-Co cemented carbides. Mater. Sci. Eng. A 2015, 645, 142-149. [CrossRef]

15. Tarragó, J.; Ferrari, C.; Reig, B.; Coureaux, D.; Schneider, L.; Llanes, L. Mechanics and mechanisms of fatigue in a WC-Ni hardmetal and a comparative study with respect to WC-Co hardmetals. Int. J. Fatigue 2015, 70, 252-257. [CrossRef]

16. Tarragó, J.; Roa, J.; Valle, V.; Marshall, J.; Llanes, L. Fracture and fatigue behavior of WC-Co and WC-CoNi cemented carbides. Int. J. Refract. Met. Hard Mater. 2015, 49, 184-191. [CrossRef]

17. Sergejev, F.; Preis, I.; Kubarsepp, J.; Antonov, M. Correlation between surface fatigue and microstructural defects of cemented carbides. Wear 2008, 264, 770-774. [CrossRef]

18. Klünsner, T.; Marsoner, S.; Ebner, R.; Pippan, R.; Glätzle, J.; Püschel, A. Effect of microstructure on fatigue properties of WC-Co hard metals. Procedia Eng. 2010, 2, 2001-2010. [CrossRef]

19. Kotas, A.B.; Danninger, H.; Weiss, B.; Mingard, K.; Sanchez, J.M.; Llanes, L. Fatigue testing and properties of hardmetals in the gigacycle range. Int. J. Refract. Met. Hard Mater. 2017, 62, 183-191. [CrossRef]

20. Roebuck, B.; Maderud, C.; Morrell, R. Elevated temperature fatigue testing of hardmetals using notched testpieces. Int. J. Refract. Met. Hard Mater. 2008, 26, 19-27. [CrossRef]

21. Ferreira, J.; Amaral, M.P.; Antunes, F.; Costa, J.; Antunes, F. A study on the mechanical behaviour of WC/Co hardmetals. Int. J. Refract. Met. Hard Mater. 2009, 27, 1-8. [CrossRef]

22. Li, A.; Zhao, J.; Wang, D.; Gao, X.; Tang, H. Three-point bending fatigue behavior of WC-Co cemented carbides. Mater. Des. 2013, 45, 271-278. [CrossRef]

23. Mikado, H.; Ishihara, S.; Oguma, N.; Kawamura, S. On the Short Surface Fatigue Crack Growth Behavior in a Fine-Grained WC-Co Cemented Carbide. Metals 2017, 7, 254. [CrossRef]

24. Liu, S.-Y.; Chen, I.-W. Fatigue of yttria-stabilized zirconia: I-Fatigue damage, fracture origins, and lifetime prediction. J. Am. Ceram. Soc. 1991, 74, 1197-1205. [CrossRef]

25. Steffen, A.A.; Dauskardt, R.H.; Ritchie, R.O. Cyclic Fatigue Life and Crack-Growth Behavior of Microstructurally Small Cracks in Magnesia-Partially-Stabilized Zirconia Ceramics. J. Am. Ceram. Soc. 1991, 74, 1259-1268. [CrossRef]

26. Torres, Y.; Tarragó, J.; Coureaux, D.; Tarrés, E.; Roebuck, B.; Chan, P.; James, M.; Liang, B.; Tillman, M.; Viswanadham, R.; et al. Fracture and fatigue of rock bit cemented carbides: Mechanics and mechanisms of crack growth resistance under monotonic and cyclic loading. Int. J. Refract. Met. Hard Mater. 2014, 45, 179-188. [CrossRef]

27. Tarragó, J.; Coureaux, D.; Torres, Y.; Casellas, D.; Al-Dawery, I.; Schneider, L.; Llanes, L. Microstructural effects on the R-curve behavior of WC-Co cemented carbides. Mater. Des. 2016, 97, 492-501. [CrossRef]

28. Fischmeister, H.; Schmauder, S.; Sigl, L. Finite element modelling of crack propagation in WC-Co hard metals. Mater. Sci. Eng. A 1988, 105, 305-311. [CrossRef]

29. Erling, G.; Kursawe, S.; Luyckx, S.; Sockel, H.G. Stable and unstable fracture surface features in WC-Co. J. Mater. Sci. Lett. 2000, 19, 437-438. [CrossRef]

30. Il Padula, S.A.; Shyam, A.; Ritchie, R.O.; Milligan, W.W. High frequency fatigue crack propagation behavior of a nickel-base turbine disk alloy. Int. J. Fatigue 1999, 21, 725-731. [CrossRef]

31. Jiang, L.; Brooks, C.; Liaw, P.; Klarstrom, D.; Rawn, C.; Muenchen, B.; Muenchen, R. Phenomenological aspects of the high-cycle fatigue of ULTIMET ${ }^{\circledR}$ alloy. Mater. Sci. Eng. A 2001, 316, 66-79. [CrossRef]

32. Chen, Q.; Kawagoishi, N.; Wang, Q.; Yan, N.; Ono, T.; Hashiguchi, G. Small crack behavior and fracture of nickel-based superalloy under ultrasonic fatigue. Int. J. Fatigue 2005, 27, 1227-1232. [CrossRef]

33. Suresh, S. Fatigue of Materials, 1st ed.; Cambridge University Press: New York, NY, USA, 1991; pp. $190-221$.

34. Sigl, L.; Fischmeister, H. On the fracture toughness of cemented carbides. Acta Met. 1988, 36, 887-897. [CrossRef] 
35. Tarragó, J.; Roa, J.; Jimenez-Pique, E.; Keown, E.; Fair, J.; Llanes, L. Mechanical deformation of WC-Co composite micropillars under uniaxial compression. Int. J. Refract. Met. Hard Mater. 2016, 54, 70-74. [CrossRef]

36. Roa, J.; Jimenez-Pique, E.; Tarragó, J.; Sandoval, D.A.; Mateo, A.; Fair, J.; Llanes, L. Hall-Petch strengthening of the constrained metallic binder in WC-Co cemented carbides: Experimental assessment by means of massive nanoindentation and statistical analysis. Mater. Sci. Eng. A 2016, 676, 487-491. [CrossRef]

37. Naughton-Duszová, A.; Csanádi, T.; Sedlák, R.; Hvizdoš, P.; Dusza, J.; Duszová, N. Small-Scale Mechanical Testing of Cemented Carbides from the Micro- to the Nano-Level: A Review. Metals 2019, 9, 502. [CrossRef]

38. Sandoval, D.A.; Rinaldi, A.; Notargiacomo, A.; Ther, O.; Tarrés, E.; Roa, J.; Llanes, L. Influence of specimen size and microstructure on uniaxial compression of WC-Co micropillars. Ceram. Int. 2019, 45, 15934-15941. [CrossRef]

(C) 2019 by the author. Licensee MDPI, Basel, Switzerland. This article is an open access article distributed under the terms and conditions of the Creative Commons Attribution (CC BY) license (http://creativecommons.org/licenses/by/4.0/). 